\title{
ANÁLISE DO MATERIAL DIDÁTICO PROBIO-EDUCAÇÃO AMBIENTAL COM FOCO NA TRANSVERSALIDADE CURRICULAR DO TEMA MEIO AMBIENTE
}

Edmar Geraldo de Oliveira ${ }^{1}$

Carlos Hiroo Saito ${ }^{2}$

Resumo: Este artigo de caráter teórico tem como proposta discutir a importância do material didático produzido pelo subprojeto "Educação Ambiental - PROBIO", com foco na transversalidade da Educação Ambiental, à luz dos Parâmetros Curriculares Nacionais (PCNs) no currículo do Ensino Fundamental. Para tanto, utilizou-se de trabalhos acadêmicos publicados resultantes de experiências no uso do material. Os relatos apresentados evidenciam que o uso do material contribui para que professores, pedagogos e alunos possam trabalhar a educação ambiental como tema transversal no currículo escolar sob a perspectiva da concepção Freireana de situaçãoproblema.

Palavras-chave: Probio, Educação ambiental, Transversalidade.

${ }^{1}$ Instituto Federal de Educação, Ciência e Tecnologia de Minas Gerais. E-mail: edmar@ifmg.edu.br

${ }^{2}$ Universidade de Brasília. E-mail: carlos.h.saito@hotmail.com

Revbea, São Paulo, V.9, Nº 2: 225-238, 2014.

revista brasileira

educação ambiental 


\section{Introdução}

A sociedade atual têm-se consolidado sob um modelo de civilização alicerçado no desenvolvimento industrial e tecnológico, na mecanização da agricultura, no uso intenso de agrotóxicos, na concentração populacional nas cidades e principalmente no consumo em larga escala. Este modelo exerce forte pressão antrópica sobre o meio ambiente destruindo boa parte dos recursos naturais e frequentemente veem-se estampadas na mídia manchetes sobre desastres ambientais. No Brasil a mais recente delas ocorreu em janeiro de 2011 quando fortes chuvas castigaram a região Serrana do Rio de Janeiro, o que provocou a morte de centenas de pessoas e deixou milhares de desabrigados. Minimizar os impactos ambientais e buscar solução para os problemas advindos da relação predatória em relação à natureza tem sido considerado cada vez mais urgente a fim de garantir o futuro da humanidade. Esta postura depende da relação estabelecida entre sociedade e natureza, tanto na dimensão coletiva quanto na individual.

Neste contexto dar-se-á ênfase, neste artigo, em duas questões preponderantes na análise do material didático Educação Ambiental (PROBIOEA), que são: a conservação da biodiversidade e a educação ambiental. A primeira delas diz respeito à biodiversidade brasileira, haja vista que esta é a base da sustentabilidade dos ecossistemas naturais, dos serviços ambientais, dos recursos florestais e pesqueiros, da agricultura e da nova indústria da biotecnologia que movimenta grandes cifras de recursos financeiros. A segunda questão abordada é a educação ambiental, considerando-se que esta é uma das principais ferramentas que podem contribuir para modificar um quadro de crescente degradação socioambiental. Nesse sentido cabe destacar que a educação ambiental "assume cada vez mais uma função transformadora, na qual a co-responsabilização dos indivíduos torna-se um objetivo essencial para promover um novo tipo de desenvolvimento - o desenvolvimento sustentável" (JACOBI, 2003, p.193).

\section{Breves considerações sobre a biodiversidade}

A importância que a biodiversidade tem assumido nos últimos tempos não reflete apenas a antiga relação que o homem tem com a natureza, no processo denominado de biofilia, em que Wilson (1996) descreve-a como uma tendência natural ao voltarmos nossa atenção às coisas vivas, mas também no conhecimento atual que as pessoas possuem do ambiente e a consciência de que a sua perda pode acarretar problemas para esta e para as futuras gerações.

Conhecer a biodiversidade, seus valores ecológicos, genéticos, sociais, econômicos, científicos, recreativos e estéticos, é o primeiro passo em direção à sua conservação e preservação (SOUZA et al., 2002). A diversidade biológica está diretamente relacionada com a manutenção do meio ambiente equilibrado do ponto de vista ecológico. Para alcançar este objetivo, além da organização do poder público para orientar, legislar e fiscalizar as ações que Revbea, São Paulo, V.9, № 2: 225-238, 2014. 
possam impactar o meio ambiente é preciso que haja um movimento de conscientização de toda a sociedade e as instituições de ensino têm papel fundamental neste processo. A escola é o espaço ideal para que seja promovido o debate e as reflexões sobre as questões ambientais no sentido de subsidiar a formação de opinião, construção de valores e principalmente a promoção da mudança de comportamento (ALVES; COLESANTI, 2006). Estas questões são fundamentais para que sejam construídos caminhos alternativos para solução ou mitigação dos grandes problemas ambientais. É fundamental que cada aluno desenvolva as suas potencialidades e adote posturas pessoais e comportamentos sociais construtivos, colaborando de forma efetiva para a conservação da biodiversidade.

A alteração e a perda de biodiversidade ocasionada por atividades antropogênicas afetam negativamente as funções dos ecossistemas, que são encarregados de prover serviços ambientais, tanto das demais espécies silvestres como do ser humano. Segundo Rêgo (2008), uma grande parte dos cientistas concorda que o impacto humano sobre a biodiversidade tem aumentado substancialmente, sendo consenso que as taxas com que os seres humanos estão alterando o ambiente, a extensão destas alterações e suas consequências para a distribuição e abundância das espécies, sistemas ecológicos e variabilidade genética são sem precedentes na história da humanidade.

O Programa das Nações Unidas para o Meio Ambiente lançou em maio de 2010, a terceira edição do relatório Panorama Global da Biodiversidade, que mapeou a situação da fauna e flora em todo o mundo. $O$ estudo mostrou que a diversidade de seres vivos no planeta continua a ser desgastada como resultado de atividades humanas. Os resultados apontam que a quantidade de espécies de vertebrados, sobretudo de água doce, diminuiu quase um terço nos últimos trinta anos e que $85 \%$ dos recifes de ostras foram extintos no mundo (PNUMA, 2010). A revista Science publicou em (2006) um estudo, dirigido pelo cientista Boris Worm, do Departamento de Biologia da Universidade Dalhousie do Canadá, onde também revela que a diminuição da diversidade marinha fez aumentar o desaparecimento de recursos e diminuir de forma exponencial o potencial de recuperação, a estabilidade e a qualidade de águas nos oceanos ${ }^{3}$. A diminuição da biodiversidade tem sido objeto de estudo de outros autores como, por exemplo, Turner, (1996); Oliveira et al., (2004); Develey e Pongiluppi (2010), os quais são enfáticos com relação à necessidade de reversão do cenário atual de forma a atingir uma redução significativa na taxa de perda de biodiversidade.

Portanto, a preservação e/ou conservação da biodiversidade deve ser de interesse coletivo e globalizado, já que ela constitui o alicerce de nossa existência. A Sociedade para a Biologia da Conservação (SCB) acredita que o ensino da conservação é passo necessário para que tais problemas sejam corrigidos. Felizmente percebe-se que nos últimos anos algumas ações

${ }^{3}$ Disponível em http://noticias.ambientebrasil.com.br-acessado em 07/06/2011.

Revbea, São Paulo, V.9, N²: 225-238, 2014.

revista brasileira

educação

ambiental 
importantes foram implementadas no sentido de garantir a manutenção da diversidade biológica. No Brasil, um exemplo positivo neste sentido foi a promulgação do decreto presidencial $n^{\circ}$ 4.339, de 22 de agosto de 2002 que instituiu os princípios e diretrizes para a implementação da Política Nacional da Biodiversidade (PNB). Outra ação importante e que merece registro foi a decisão da Assembleia Geral das Nações Unidas em declarar 2010 como o ano internacional da biodiversidade para conscientizar sobre a importância da biodiversidade para o planeta. A iniciativa teve como princípios básicos ${ }^{4} 0$ de expressar a importância da biodiversidade para o bem estar das populações, estimular a reflexão sobre as conquistas alcançadas até agora para preservar a biodiversidade e principalmente para maximizar os esforços no sentido de reduzir o índice de perda da biodiversidade.

\section{Educação ambiental: sensibilização, conscientização e mobilização}

Os Parâmetros Curriculares Nacionais - PCNs (1997, p. 180) ao tratar da educação como elemento indispensável para a transformação da consciência ambiental afirmam que uma das principais conclusões e proposições assumidas em reuniões internacionais ${ }^{5}$ é a "recomendação de investir numa mudança de mentalidade, conscientizando os grupos humanos da necessidade de adotar novos pontos de vista e novas posturas diante dos dilemas e das constatações feitas nessas reuniões". O desenvolvimento da consciência ambiental, em nível internacional, ficou marcado por meio de duas importantes Conferências promovidas pelo programa das Nações Unidas para o Meio Ambiente na década de 70. De acordo com Sato (1995) a partir da Conferência de Estocolmo (1972) e de Tbilisi (1977), a literatura tem enfatizado a importância da redefinição da educação ambiental, conduzindo os diversos profissionais, de diferentes áreas, a interagirem, centralizando as discussões da mesma dentro de uma perspectiva interdisciplinar.

No Brasil foi também a partir da década de 70, possivelmente por influência das grandes conferências internacionais, que se iniciou o crescimento dos movimentos ambientalistas. Desde então passou-se a adotar explicitamente a expressão "educação ambiental" para qualificar iniciativas de universidades, escolas, instituições governamentais e não governamentais por meio das quais se busca conscientizar setores da sociedade para as questões ambientais. Percebeu-se que a educação ambiental é um instrumento

4 Disponível em http://www.unesco.org/pt/brasilia/about-the-unesco-brasilia-office/prizes-andcelebrations-in-brazil/2010-international-year-of-biodiversity/ Acesso em 05/02/2011.

${ }^{5}$ Entre as principais reuniões internacionais podemos citar a Conferência das Nações Unidas para o Meio Ambiente Humano - Estocolmo (1972), 1ํㅡㄹ Conferência Intergovernamental Sobre Educação Ambiental em Tbilisi (1977), Conferência Internacional sobre Educação e Formação Ambiental - Moscou (1987), Conferência das Nações Unidas sobre Meio Ambiente e Desenvolvimento - Rio de Janeiro (1992) e a Conferência da Cúpula Mundial para o Desenvolvimento Sustentável - Johanesburgo (2002).

Revbea, São Paulo, V.9, № 2: 225-238, 2014. 
importante, visto que, dentre seus objetivos está o de preparar o indivíduo para interagir criticamente com seu semelhante e com o meio, questionando a sociedade e transformando sua visão de mundo de forma a melhorar sua qualidade de vida (PERES; MENDONÇA, 1991 apud FERREIRA, 1999).

Um marco importante neste processo diz respeito à aprovação e promulgação em 1999 da lei 9.795 que institucionaliza a Educação Ambiental, define responsabilidades e insere o tema na pauta dos diversos setores da sociedade, legalizando assim seus princípios, transformando-a em objeto de políticas públicas, além de proporcionar à sociedade um instrumento de cobrança para a promoção da educação ambiental. De acordo com Art. $1^{\circ}$ da lei $\mathrm{n}^{\circ} 9.795$ "entende-se por educação ambiental os processos por meio dos quais o indivíduo e a coletividade constroem valores sociais, conhecimentos, habilidades, atitudes e competências voltadas para a conservação do meio ambiente, bem de uso comum do povo, essencial à sadia qualidade de vida e sua sustentabilidade".

Para Santos (2002) a Educação Ambiental se constrói, fundamentalmente, em três momentos básicos de transformação: a sensibilização, a conscientização e a mobilização. Podemos observar que uma ação condiciona a outra. Não se pode conscientizar sem antes sensibilizar e, da mesma maneira não se pode mobilizar sem antes ter sensibilizado e conscientizado. Estes três momentos são tratados na lei $n^{\circ} 9.795$, onde o inciso VI do art. $3^{\circ}$ estabelece que a sociedade como um todo deva manter atenção permanente à formação de valores, atitudes e habilidades que propiciem a atuação individual e coletiva voltada para a prevenção, a identificação e a solução de problemas ambientais. Ainda no art. 13 enfatiza a importância de ações e práticas educativas voltadas à sensibilização da coletividade sobre as questões ambientais e à sua organização e participação na defesa da qualidade do meio ambiente.

Neste contexto é importante que a educação ambiental esteja presente em todos os níveis e modalidades do processo educativo, em caráter formal e não formal. No caso da educação não formal, que aconteça preferencialmente de forma simples e atraente para que possa despertar maior interesse. Neste sentido, materiais didáticos que tratem da temática da conservação da biodiversidade, de forma sistemática e planejada, de forma a cobrir um conjunto de temas prioritários ${ }^{6}$ são importantes e necessários para problematizar essa temática nas comunidades escolares neste contexto mundial de crescentes perdas na biodiversidade.

6 Os temas eleitos prioritários pelo PROBIO e constantes da carta-convite para elaboração do material educativo são: biomas brasileiros, as espécies da fauna brasileira ameaçadas de extinção (constantes da lista oficial), fragmentação de ecossistemas, espécies exóticas invasoras, biodiversidade brasileira e Unidades de Conservação da Natureza.

Revbea, São Paulo, V.9, N²: 225-238, 2014.

revista brasileira

educação

ambiental 


\section{O material didático PROBIO e a transversalidade do meio ambiente}

O projeto de Conservação e Utilização Sustentável da Diversidade Biológica Brasileira - PROBIO teve inicio em 1996 quando o governo brasileiro e o Fundo Mundial para o Meio Ambiente assinaram um acordo de doação para a implantação do mesmo. O Projeto compreendeu o período de 1996 a 2005 e foi coordenado pelo Ministério do Meio Ambiente (MMA), tendo como objetivo identificar ações prioritárias para a conservação e uso sustentável da biodiversidade, apoiando subprojetos que promovessem parcerias entre os setores público e privado, de modo que pudesse gerar e divulgar conhecimentos e informações sobre a diversidade biológica brasileira.

No ano de 2004 o MMA lançou carta-consulta visando selecionar um subprojeto para a produção de material educativo impresso sobre a biodiversidade brasileira, que integrasse os temas eleitos prioritários pelo PROBIO. Segundo a referida carta consulta, o material produzido deveria cumprir o papel de desenvolver atividades didático-pedagógicas relacionadas à biodiversidade para os professores do Ensino Fundamental e aos seus alunos e para os educadores envolvidos em projetos de Educação Ambiental desenvolvidos localmente no país (SAITO; ALMEIDA, 2006). Entre as diversas propostas, a vencedora foi a do consórcio liderado pela Universidade de Brasília (UnB) que produziu então um conjunto articulado de material didático sobre a biodiversidade brasileira, que integra os biomas brasileiros, as espécies da fauna brasileira ameaçadas de extinção (constantes da lista oficial), a problemática da fragmentação de ecossistemas e das espécies invasoras e a importância das unidades de conservação.

O material didático produzido consta de 45 pares de portifólios, um jogo educativo de tabuleiro e um livro do professor (disponível em http://www.ecoa.unb.br/probioea/). Todo esse conjunto didático trata a temática da biodiversidade seguindo os princípios da Política Nacional de Educação Ambiental (Lei 9.795/99), que recomenda a abordagem do meio ambiente em sua totalidade, considerando a interdependência entre o meio natural, o socioeconômico e o cultural, sob o enfoque da sustentabilidade. Conforme já mencionado o material foi concebido dentro da abordagem dialógico problematizadora, inspirada em Paulo Freire, apresentando desafios para os alunos e para serem resolvidos conjuntamente, variando desde a abordagem experimental no ensino-aprendizagem até o envolvimento e participação em fóruns coletivos locais, passando por atividades de planejamento, implementação e avaliação de pesquisas em Educação Ambiental no entorno da escola (SAITO, 2008).

O elemento principal do material são os portifólios que contém fotos na frente e texto no verso e aborda os temas do PROBIO em cada um dos biomas brasileiros, segundo o binômio conflitos socioambientais (problemas ou situações-problema) e ações positivas (soluções existentes). O jogo educativo de tabuleiro está integrado aos portifólios e visa complementar, de forma lúdica, a aprendizagem por alunos e professores. O livro do professor explica conceitos chaves presentes nos portifólios e no jogo educativo de tabuleiro, Revbea, São Paulo, V.9, № 2: 225-238, 2014. 
trazendo a fundamentação teórico-metodológica por trás do trabalho produzido, bem como o aprofundamento do conteúdo conceitual dos temas prioritários em cada um dos biomas.

A equipe responsável pela elaboração do material atentou-se para o fato de que os temas abordados não terminassem isolados e fragmentados nos currículos escolares. Foram identificados então os principais eixos (ou preocupações temáticas) transversais com possibilidade de integração, para que o processo de ensino aprendizagem dos conceitos científico-tecnológicos subjacentes aos conflitos socioambientais e as respectivas ações positivas ficassem de acordo com os princípios da Política Nacional da Educação Ambiental (SAITO; ALMEIDA, 2006). Esta iniciativa vai ao encontro da abordagem preconizada pelos Parâmetros Curriculares Nacionais (PCN's, 1997), que apresentam os temas transversais (entre eles o meio ambiente) devendo os mesmos permear todos os conteúdos do currículo do ensino fundamental.

A partir da inclusão da temática ambiental como tema transversal, os PCN's ajudam no desenvolvimento da Educação Ambiental no âmbito formal, despertando o universo escolar para a importância da temática, dando-lhes a mesma importância das áreas convencionais. "O currículo ganha em flexibilidade e abertura, uma vez que os temas podem ser priorizados e contextualizados de acordo com as diferentes realidades locais e regionais e outros temas podem ser incluídos". (PCN's, 1997, p. 25).

Os temas transversais devem expressar conceitos e valores básicos à democracia e à cidadania e obedecem a questões importantes e urgentes para a sociedade contemporânea, devendo ser trabalhados de modo coordenado e não como um assunto descontextualizado nas aulas. O que importa é que os alunos possam construir significados e conferir sentido àquilo que aprendem. Quanto ao tema transversal meio ambiente, devemos lembrar que não se reduz apenas ao ambiente físico e biológico, mas abrange também as relações sociais, econômicas e culturais ${ }^{7}$. Através dessa visão devemos propiciar momentos de reflexões que induzam os alunos ao enriquecimento cultural, à qualidade de vida e à preocupação com o equilíbrio ambiental. (HAMZE, 2011). Sob este prima Saito (2006 p.4) afirma "que o conhecimento não deve servir apenas à contemplação, mas também ao desenvolvimento pessoal e coletivo pró-ativo, engajado e responsável'; corroborando, desta forma, com a lei 9.795 que estabelece no inciso III do art. $5^{\circ}$ um dos objetivos fundamentais da educação ambiental "o estímulo e o fortalecimento de uma consciência crítica sobre a problemática ambiental e social".

Nesse sentido, o material didático Educação Ambiental PROBIO apresenta desafios a serem problematizados no ambiente escolar, uma vez que, as situações/problema estruturam-se em torno de situações reais retratadas nos portifólios, relacionadas aos diversos biomas dentro de universos temáticos específicos e são apresentadas de forma a ser objeto de

7 Hamze, A. disponível em http://educador.brasilescola.com/ - acesso em 10/02/2011.

revista brasileira educação ambiental 
estudo, permitindo assim a contextualização entre o conteúdo abordado e as situações vivenciadas pelos alunos em seu cotidiano. De acordo com Almeida, Oliveira e Saito (2010) o material contribui e facilita o trabalho com a educação ambiental na sala de aula, possibilitando o tratamento transversal do tema em vários momentos. Na sequência serão apresentadas considerações sobre experiências no uso do material didático e que resultaram em cinco publicações diferentes de trabalhos acadêmicos e científicos.

A professora Rosimeri Henn em sua dissertação de mestrado (2008) pela Universidade Federal de Santa Maria (RS) abordou a temática "desafios ambientais na educação infantil". O estudo teve como objetivo adaptar os materiais didáticos produzidos pelo $\mathrm{PROBIO}$ à prática contextualizada na organização curricular e no trabalho do dia-a-dia dos professores e alunos de Educação Infantil, numa construção do conhecimento ambiental. O material foi adaptado para trabalhar-se com crianças na faixa etária de 4 e 5 anos e apesar de ter-se trabalhado apenas com o bioma Campos Sulinos, os resultados apontaram importantes considerações que poderão subsidiar outros estudos ou experiências no uso do material.

Segundo Henn (2008) os temas abordados pelo PROBIO apresentam uma proposta de ensino transversal, diferenciando-se dos modelos de currículos já estabelecidos na escola geralmente de cunho disciplinar. Para Henn (2008 p.95) "este material visa à contextualização entre os conteúdos científicos e os saberes populares, juntamente com a preocupação social'. Para ilustrar este argumento apresenta-se a seguir uma das estratégias didáticas apresentadas no livro do professor. Trata-se da construção de uma matriz de conhecimento para a visualização do conjunto dos portifólios organizada com sete colunas representando os biomas e seis linhas representando os temas. Nesta atividade permite-se trabalhar de forma coordenada, onde é possível perceber que alguns problemas são comuns a mais de um bioma e repercutem em temas diferentes e outras vezes em temas semelhantes. A realização desta atividade com a orientação do professor permite aos alunos visualizar as interconexões entre os diferentes problemas e/ou soluções para os diversos biomas, fazer associações com situações problemas no entorno da escola e entender a fundamentação científicotecnológica dos fatos e/ou fenômenos.

O segundo relato de experiência no uso do material teve inicio em novembro de 2009 quando a UnB realizou um curso de capacitação para professores de Ensino Fundamental e Médio de escolas da rede pública e privada do Distrito Federal, específico sobre o material didático do PROBIO-EA (NÓBREGA et al., 2011). A partir deste curso professores do Centro de Ensino Médio 02 do Gama/DF elaboraram um projeto com objetivo de avaliar 0 potencial mediador do referido material didático. O trabalho foi desenvolvido ao longo do ano de $2010 \mathrm{com}$ dez turmas de $2^{\circ}$ ano do ensino médio, durante as aulas de geografia. Após conhecer e estudar o material do PROBIO-EA os alunos foram estimulados a reelaborar os seus próprios portifólios para retratar 
os conflitos socioambientais e ações positivas observadas no entorno da escola e localidades onde residiam.

De acordo com Nóbrega et al. (2011) os resultados do projeto no Centro de Ensino Médio 02 do Gama/DF demonstram que "o material PROBIO-EA funcionou como mediador e que a partir da utilização do mesmo, os estudantes foram capazes de perceber os conflitos socioambientais encontrados na escola" (Ibid p. 2). A reelaboração dos portifólios permitiu também que "os alunos se reconhecessem como os protagonistas de possíveis ações e para isto devem se mobilizar para propor ações positivas seja na escola ou no seu bairro, na sua comunidade" (Ibid p. 2).

A utilização do material educação ambiental PROBIO resultou em outra experiência que se deu ao longo do ano de 2010 e foi desenvolvido pelo Colégio Santa Rosa em Brasília-DF, onde realizou-se um projeto para uma turma de "7ํa ano / 6" série" do ensino fundamental, na disciplina de Geografia (D'ALMEIDA et al, 2011). Todos os biomas foram objeto de estudo, porém foi dada uma maior ênfase ao bioma cerrado, o qual faz parte do cotidiano dos alunos. Uma das etapas consistiu numa visita de campo dos alunos ao Parque Nacional da Chapada dos Veadeiros-GO, ocasião em que estes puderam entrar em contato com as comunidades tradicionais da região (quilombolas), o que permitiu estabelecer uma ponte intercultural, com a presença de quilombolas na mostra cultural realizada posteriormente na sede da escola. Os banners produzidos pelos alunos sobre a flora do bioma cerrado e a problematização do entorno do Parque Nacional da Chapada dos VeadeirosGO foram expostos na mostra cultural da escola, cujo tema central foi sustentabilidade.

De acordo com D'Almeida et al. (2011), o material didático permitiu fazer uma relação direta entre os assuntos estudados envolvendo o ser humano e o meio ambiente, o que não ocorre comumente nos livros de geografia, quando os temas na maioria das vezes são apresentados em separado. Nas palavras desses autores "o material possibilitou o conhecimento paralelo de outras áreas do conhecimento que não correspondem especificamente ao conteúdo da disciplina, mas que conduz à interdisciplinaridade" (Ibid p. 2). Os autores do trabalho afirmam ainda que a utilização do material contribuiu para "integrar outras disciplinas por meio da inserção transversal da temática meio ambiente no currículo, com atividades que terminaram por envolver os demais professores para a exposição na Mostra Cultural da escola com temas ambientais" (D'ALMEIDA et al., 2011, p. 8).

Henn (2008) em sua pesquisa com crianças no Rio Grande do Sul identificou claramente situações que demonstram como o material pode contribuir para o aprendizado sobre os assuntos propostos. A pesquisadora relata que "... conforme íamos chegando ao final dos temas sobre os Campos Sulinos, os debates proporcionados foram ficando melhores elaborados e o próprio diálogo era acrescido com diferentes idéias, sendo que as crianças relacionavam os temas, problemas e soluções". (p. 400). 
No material didático $\mathrm{PROBIO}$-EA percebe-se a relação entre o texto e as fotos, as quais expressam, visualmente, muito bem a analogia do conflito e da ação positiva, auxiliando no processo de conscientização ambiental. Saito (2008) confirma que as situações-problema são organizadas nos portifólios de modo a chamar a atenção dos alunos e professores para a relação entre fotos e textos guardando em si elementos e relações. Estas serão compreendidas através de interações dialógicas ou debates nas aulas pelos alunos, com a orientação dos educadores, tendo por base os conhecimentos científicotecnológicos e os tradicionais. Neste contexto, Henn (2008) destaca a importância do professor no processo de ensino aprendizagem. "A mediação do professor é fundamental no desenvolvimento do trabalho, pois sem os planejamentos, a contextualização, os questionamentos, levantados por nós frente aos portifólios, as fotos e o material por si, sozinhos, isolados, não teriam a mesma eficiência". (Ibid p. 403).

Outra experiência no uso do material aconteceu no Rio Grande do Sul, onde Nardin (2011) em sua dissertação de mestrado pela UFMS-RS avaliou o potencial mediador dos materiais didáticos $\mathrm{PROBIO}-\mathrm{EA}$ para a abordagem do tema transversal meio ambiente por meio do ambiente virtual de ensinoaprendizagem livre Moodle ${ }^{8}$. O material didático foi inserido como recurso em ferramentas de atividade colaborativa como a wiki, no intuito de dotá-lo de características hipermidiáticas. Após a estruturação do material no Moodle, na perspectiva da investigação-ação educacional, foi implementado um curso com professores das séries finais da escolaridade fundamental, objetivando problematizar os conceitos-chaves ambientais e avaliar, de forma colaborativa, as potencialidades dos materiais PROBIO-EA para suscitar o diálogo em torno do tema transversal meio ambiente.

Mesmo com a disponibilidade do material na internet, este trabalho abre mais uma possibilidade de acesso livre e com foco ampliado ao mesmo, uma vez que, verifica-se um vertiginoso crescimento da internet, ampliando a conectividade, constituindo redes e substituindo outras tecnologias (BRASIL/MCT, 2000). Por conseguinte, Nardin (2011) considerando os resultados proporcionados pelo estudo, afirma que "as análises e reflexões suscitadas destacam potencial significativo dos referidos materiais para romper com práticas transmissivas, em prol do diálogo-problematizador sobre situações-problemas" (Ibid p. 7).

Considerando a complexidade do tema meio ambiente, é essencial salientar a importância de o ensino formal, utilizar também os espaços nãoformais como complementares às suas estratégias de conscientização ambiental, garantindo o maior envolvimento dos alunos com a questão ambiental. Sob esta perspectiva o material didático PROBIO-EA, em especial o

${ }^{8}$ Desenvolvido por Dougiamas (1990), o Moodle foi concebido com o intuito de servir de ambiente para a aprendizagem colaborativa, integrando uma perspectiva construtivista. Nesse sentido, o desenvolvimento do Moodle orienta-se por uma "filosofia de aprendizagem", que compreende quatro conceitos principais: construtivismo, construcionismo, construcionismo social e comportamento conectado e destacado (NARDIN, 2011).

Revbea, São Paulo, V.9, N²: 225-238, 2014. 
jogo educativo do tabuleiro, apresenta-se como uma alternativa interessante, haja vista que trata-se de uma atividade em grupo que promove o aprendizado por meio do envolvimento lúdico e prazeroso, a partir do desenvolvimento de uma dinâmica baseada em regras pré-definidas que definem o seu contexto. Estes aspectos puderam ser observados na prática, durante o desenvolvimento do projeto PROBIO-EA na praça e na escola (SAITO et al., 2011).

Por meio deste projeto foram realizadas exposições em praças públicas de diversas cidades brasileiras com o objetivo de difundir e popularizar o conhecimento científico e tecnológico sobre a conservação da biodiversidade tendo como ferramenta o material didático PROBIO-EA. As exposições foram organizadas de modo a contemplar todos os biomas, sendo realizadas nas seguintes cidades: Manaus-AM, Jacobina-BA, Ilhéus-BA, Itabuna-BA, GoiâniaGO, Brasília-DF, Rondonópolis-MT, Santa Maria-RS e Tamandaré-PE. O jogo foi convertido em tabuleiro gigante em lona para os presentes brincarem sendo as próprias peças do jogo e de acordo com Saito et al. (2011, p. 6) "tal iniciativa foi bem aceita pela comunidade, uma vez que despertou o interesse de crianças, jovens e adultos" que participaram com grande entusiasmo.

O jogo educativo tem como objetivos, "reforçar a motivação para 0 estudo, através de atividades dramáticas e lúdicas", "educar para a tomada de decisões", e "educar o impulso competitivo para a solidariedade e cooperação" (SAITO, 2006, p.18). A estruturação do jogo com o tabuleiro colorido e representando os diversos biomas, os dados, o dinheiro "fictício" e os oito animais da biodiversidade brasileira ${ }^{9}$ que precisam ser salvos são atrativos que chamam a atenção e despertam o interesse dos alunos. Vale destacar que o jogo educativo de tabuleiro está integrado aos portifólios e visa complementar, de forma lúdica, a aprendizagem por alunos e professores.

\section{Conclusões}

Os estudos relatados neste artigo resultantes das experiências do uso do material didático PROBIO-EA evidenciam sua importante contribuição para os profissionais da educação e alunos ao se trabalhar a temática ambiental como tema transversal no currículo escolar. A análise do uso do material didático permitiu identificar em diversas situações que o mesmo atende aos princípios da transversalidade no ensino infantil e fundamental. A apresentação dos conteúdos na forma de resolução de conflitos cotidianos e a articulação entre os temas abordados possibilitam aos alunos atribuir significado a aprendizagem.

\footnotetext{
${ }^{9}$ Dos oito animais que precisam ser salvos, seis estão na Lista Nacional das Espécies da Fauna Brasileira Ameaçadas de Extinção do Ministério do Meio Ambiente. São eles: Arara azul de Lear (Caatinga), Muriqui do Norte (Mata Atlântica), Peixe-boi marinho (Ambientes Costeiro e Marinho), Caboclinho-do-chapéu-cinzento (Campos Sulinos) Ariranha (Pantanal), Lobo Guará (Cerrado), Tracajá (Amazônia), Ratão do banhado (Campos Sulinos - representante dos Temas Especiais).
} 
O material didático PROBIO-EA está disponível livremente na internet através do portal eletrônico http://www.ecoa.unb.br/probioea/ podendo ser baixado para consultas, utilização impressa ou através de recursos multimídia. Contudo há necessidade de uma maior divulgação, uma vez que a tiragem foi limitada e muitas escolas não receberam o material; com isto muitos profissionais da educação desconhecem sua existência.

Ao finalizar reporto-me aos professores Saito (2006) e Henn (2008) para dizer que apesar da amplitude e riqueza do material didático, o mesmo não pode ser visto e, muito menos utilizado como modelo pronto, "receita de bolo" a ser seguida, mas que possa estimular professores e alunos a identificar, na sua própria região, conflitos socioambientais e ações positivas, e que isso lhes desperte o gosto pela busca do conhecimento e propicie a aplicação deste aprendizado em ações concretas, somando-se a outras ações já em curso na região. Ressalte-se ainda que o material didático Educação Ambiental PROBIO tem como propósito a contribuição para o bem comum, sendo natural e necessário o seu enriquecimento com o tempo pelas contribuições de educadores e educandos que venham a utilizá-lo, conhecê-lo, modificá-lo, criticá-lo e distribuí-lo.

\section{AGRADECIMENTOS}

Ao Instituto Federal de Educação, Ciência e Tecnologia de Minas (IFMG) e ao Programa de Pós-Graduação em Ciências Ambientais da Universidade Federal de Goiás (CIAMB/UFG) por tornarem possível o doutoramento do primeiro autor deste artigo. Ao CNPq, pelo apoio ao segundo autor na forma de bolsa de produtividade em pesquisa.

\section{REFERÊNCIAS}

ALMEIDA, A.S.V., OLIVEIRA, L.G., SAITO, C.H. A contribuição do material do PROBIO / EA e seu potencial no Ensino de Ciências e Biologia. Revista da SBEnBIO. , v.3, p.3105 - 3114, 2010.

ALVES, A.L.; COLESANTI, M.T.M. A importância da Educação Ambiental e sua prática na Escola como Meio de Exercício da Cidadania. Uberlândia: Universidade Federal de Uberlândia. Disponível em: http://www.seer.ufu.br/index.php/horizontecientifico/article/viewFile/3878/2883.

Acesso em: 10 fev. 2011.

BRASIL/MC. Sociedade da informação no Brasil: livro verde / organizado por Tadao Takahashi. Brasília: Ministério da Ciência e Tecnologia, 2000.

Brasil, Lei no 9.795 de 27 de abril de 1999 que dispõe sobre a Política Nacional de Educação Ambiental. disponível em: http://www.planalto.gov.br/ccivil 03/Leis/ acesso em 16/01/2011.

Brasil, Decreto 4.339/2002, de 22 de agosto de 2002, que institui princípios e diretrizes para implementação da Política Nacional da Biodiversidade. 
Brasil, Ministério da Educação. Secretaria da Educação Fundamental. Parâmetros curriculares nacionais. temas transversais: meio ambiente e saúde. v. 9. Brasília: MEC/SEF, 1997.

Brasil, Ministério do Meio Ambiente. Identidades da Educação Ambiental Brasileira. Brasília, 2004.

D'ALMEIDA, M.L.; FETTER, R.; GERMANOS, E.; GOMES, M.; DE OLIVEIRA, C.H.; SAITO, C.H. Utilização do material didático do PROBIO-EA em disciplina de Geografia do ensino fundamental. In: Anais da 12a Reunião Bienal da RedPop, 2011, Campinas. XII Reunión Bienal de la Red POP, 2011. Disponível em http://www.mc.unicamp.br/redpop2011/trabalhos/394.pdf. Acesso em 21/06/2011.

FERREIRA, M.A.V. Análise dos Impactos Ambientais causados pelo lixo em uma abordagem interdisciplinar para alunos do Ensino fundamental. Monografia apresentada ao Centro de Ciências Biológicas e da Saúde como requisito para obtenção do título de bacharel em Ciências Biológicas. UFSCar, São Carlos, SP. 1999.

HAMZE, A. Os Temas Transversais na Escola Básica. Disponível em http://www.educador.brasilescola.com/gestao-educacional/os-temas-

transversais-na-escola-basica.htm - acesso em 30/01/2011.

HENN, R. Desafios Ambientais na Educação Infantil. Dissertação (Mestrado em Educação). Universidade Federal de Santa Maria - UFSM/RS. 424f. 2008.

JACOBI, P. Educação Ambiental, Cidadania e Sustentabilidade. Cadernos de Pesquisa- vol. 118, p. 189-205 - Fundação Carlos Chagas, 2003.

NARDIN, A.C. Avaliação do potencial dialógico problematizador dos materiais didáticos produzidos pelo PROBIO-EA. Dissertação (Mestrado em Educação) Universidade Federal de Santa Maria. UFSM/RS. 175f. 2011.

NÓBREGA. M.D.; FETTER, R.; GERMANOS, E.; GOMES, M.R.; DE OLIVEIRA, C.H.; SAITO, C.H. Reelaboração de portifólios para análise de conflitos socioambientais locais baseado no material didático do PROBIO-EA. In: Anais da 12 ${ }^{\mathrm{a}}$ Reunião Bienal da Red-Pop, 2011, Campinas. XII Reunión Bienal de la Red POP, 2011.Disponível em http://www.mc.unicamp.br/redpop2011/trabalhos/390.pdf $\quad$ Acesso em 19/06/2011.

PNUMA. Secretariado da Convenção sobre Diversidade Biológica, Panorama da Biodiversidade Global 3, Brasília, Ministério do Meio Ambiente, Secretaria de Biodiversidade e Florestas (MMA), 94, 2010.

RÊGO, P.A. A Conservação da Biodiversidade, a proteção do conhecimento tradicional associado e a formação de um regime internacional de repartição de benefícios no âmbito da Convenção da Diversidade Biológica (CDB). Dissertação de Mestrado. Universidade Federal de Santa Catarina (UFSC). Florianópolis. 2008. 
SATO, M. Educação Ambiental. 3. ed. São Carlos, PPG-ERN, UFSCar, 1995, 52 p.il.

SAITO, C.H. (org.). Educação Ambiental PROBIO: Livro do Professor. Brasília, MMA/Departamento de Ecologia da UnB, 136p. 2006. (Inclui 90 lâminas de portifólio e um jogo educativo de tabuleiro).

SAITO, C.H., BASTOS, F.P. e ABEGG, I. Teorias-guia educacionais da produção dos materiais didáticos para a transversalidade curricular do meio ambiente do MMA. Revista Iberoamericana de Educación. ISSN: 1681-5653 n. 0 45/2 -10 de febrero de 2008

SAITO, C.H.; ALMEIDA, L.E. Conservação da Biodiversidade e a valorização do componente educacional. Floresta e Ambiente, v. 13, p.66-74, 2006.

SAITO, C. H.; BARTASSON, L. A.; GERMANOS, E.; FETTER, R.; HENKEOLIVEIRA, C.; GOMES, M. R.; DE ALMEIDA, L. E.; DUARTE, B. P.; CALDAS, A. L. R.; MACHADO, A. L. S.; DE BASTOS, F. P.; SHUVARTZ, M.; LEAL, I. O. J.; NUNES, J. B. A.; AZEVEDO, A. A.; JOSÉ, W. D.; FERREIRA, B. P.; CORRÊA, L. O. A.; NASCIMENTO, E.; DE LUCENA, E. A. R. M.; SARAVY, J. C. S.; DE FREITAS, E. C.; GUIMARÃES, P. S.; ROCHA, L. R.; BARBOSA, R. G. PROBIO-EA na praça e na escola. In: Anais da $12^{a}$ Reunião Bienal da RedPop, 2011, Campinas. XII Reunión Bienal de la Red POP, 2011. Disponível em http://www.mc.unicamp.br/redpop2011/trabalhos/359.pdf Acesso em 19/06/2011.

SANTOS, C.P. Educação Ambiental: ação e conscientização para um mundo melhor. Minas Gerais. Secretaria de Estado da Educação. Belo Horizonte: SEE/MG, 2002.

SOUZA, B.; TEIXEIRA, M., BRUGIOLO, S. Reflexões sobre Conservação e preservação da biodiversidade. Educação ambiental em perspectiva, Ed. Feme, pp 40-47. Juiz de Fora - MG, 2002.

SOUZA, R.M.G. Projetos Educativos no Instituto de Pesquisas Jardim Botânico do Rio de Janeiro: Uma prática de sensibilização para a conscientização ambiental. Dissertação (Mestrado em Engenharia de Produção). Universidade Federal Fluminense. Niterói - RJ. 82f. 2005.

WILSON, E. Biophilia and the environmental ethic. Search of nature, pp.165179, 1996. 